\title{
Gestational diabetes mellitus screening and outcomes
}

\author{
Hale Lebriz Aktün, Derya Uyan, Betül Yorgunlar, Mustafa Acet \\ Department of Obstetrics and Gynecology, Istanbul Medipol University Hospital, Istanbul, Turkey
}

\section{Abstract}

Objective: To verify the usefulness of the World Health Organization criteria for the diagnosis of gestational diabetes mellitus in pregnant women and its effectiveness in the prevention of maternal and neonatal adverse results in women younger than 35 years without apparent risk factors for gestational diabetes mellitus.

Material and Methods: This is a retrospective study based on population involving 1360 pregnant women who delivered and who were followed-up in a university hospital in Istanbul. All women underwent the 75 -g oral glucose tolerance test screening, usually in between the $24^{\text {th }}$ $28^{\text {th }}$ weeks of pregnancy. In all cases, the identification of gestational diabetes mellitus was determined in accordance with the World Health Organization criteria.

Results: Approximately $28 \%$ of the pregnant women aged younger than 35 years with no risk factors for gestational diabetes mellitus were diagnosed with the oral glucose tolerance test in this study. In the gestational diabetes mellitus group, the primary cesarean section rate was importantly higher than that in the non-gestational diabetes mellitus group. Preterm delivery was also associated with gestational diabetes mellitus. The diagnosis of gestational diabetes mellitus was strongly associated with admittance to the neonatal intensive care unit. Neonatal respiratory problems didn't showed any significant deviation between the groups. There was a moderate association between gestational diabetes mellitus and metabolic complications.

Conclusion: Pregnant women with no obvious risk factors were diagnosed with gestational diabetes mellitus using the World Health Organization criteria. The treatment of these women potentially reduced their risk of adverse maternal and neonatal hyperglycemia-related events, such as cesarean section, polyhydramnios, preterm delivery, admission to neonatal intensive care unit, large for gestational age, and higher neonatal weight. (J Turk Ger Gynecol Assoc 2015; 16: 25-9)

Keywords: Gestation, diabetes mellitus, pregnancy, oral glucose tolerance test, neonatal outcomes

Received: 25 July, 2014

Accepted: 10 January, 2015

\section{Introduction}

Gestational diabetes mellitus (GDM) is defined as carbohydrate intolerance with onset or first recognition during pregnancy (1). GDM is currently the most frequently diagnosed metabolic disorder in pregnant women (2), and its incidence is growing (3).

GDM is associated with several adverse pregnancy outcomes with macrosomia, shoulder dystocia, and neonatal hypoglycemia being the most common serious complications.

Currently, there is no consensus on the screening criteria for GDM, and no specific universally accepted protocol exists with respect to the selective or global screening of pregnant women. Consequently, it is difficult to compare the prevalence of GDM among various populations. In particular, ethnicity has been proven to be an independent risk factor for $\operatorname{GDM}(4,5)$. The goals of this study were to verify the usefulness of the World Health Organization (WHO) criteria for the diagnosis of GDM in a fragment of local population and the effectiveness of these criteria in preventing maternal and neonatal adverse outcomes in women younger than 35 years old without obvious risk factors for GDM.

\section{Material and Methods}

This was a retrospective population-based study involving 1360 pregnant women who delivered and who were observed in a university hospital in Istanbul from September 2012 to October 2013. Ethics Committee approval and informed consent has been taken.

All the subjects were younger than 35 years and had no known risk factors for GDM. Women having chronic systemic illnesses, preexisting diabetes (type 1 or type 2), or multifetal gestations were excluded. All the women underwent oral glucose tolerance test (OGTT) screening between 24 and 28 weeks of pregnancy, and ultrasound examination was made to determine gestational age. In all cases, GDM was diagnosed according to the WHO criteria $(4,5)$. After a minimum of $8 \mathrm{~h}$ of overnight fasting, blood for glucose level determination was collected, after which the patient received 75 g glucose orally. An additional blood sample was collected for glucose level determination $2 \mathrm{~h}$ later. The WHO criteria define GDM as a fasting blood glucose $>126 \mathrm{mg} / \mathrm{dL}$, with a 2 $\mathrm{h}$ post dosing value $>140 \mathrm{mg} / \mathrm{dL}$. In case of GDM diagnosis, the patients underwent individualized diet and/or insulin 
Table 1. Anthropometric, clinical, and biochemical features of all pregnant women in the study

\begin{tabular}{|c|c|c|c|}
\hline & GDM $(n=380)$ & No GDM $(n=980)$ & p value \\
\hline BMI $\left(\mathrm{kg} / \mathrm{m}^{2}\right)$ & $22.9 \pm 1.9$ & $21.4 \pm 1.9$ & $<0.001$ \\
\hline Week at OGTT & $27.1 \pm 1.2$ & $27.1 \pm 0.8$ & 0.230 \\
\hline Fasting glucose (mg/dL) & $91.4 \pm 8.97$ & $79.4 \pm 5.7$ & $<0.001$ \\
\hline Weight gain at OGTT (kg) & $9.8 \pm 3.4$ & $7.0 \pm 2.7$ & $<0.001$ \\
\hline Weight gain at delivery (kg) & $14.3 \pm 3.3$ & $12.0 \pm 2.7$ & $<0.001$ \\
\hline
\end{tabular}

treatment with self-observing of blood glucose levels (fasting and $1 \mathrm{~h}$ after each meal) daily with a glucometer. Subsequent follow-ups were conducted for all patients biweekly or more frequently as indicated. Treatment outcomes were evaluated according to the American Diabetes Association recommendations (6).

All demographic characteristics (age, parity, family history of diabetes, and self-reported prepregnancy weight) of the patients were obtained from their existing records. Birth mode (cesarean or vaginal delivery) and labor induction, preterm delivery (delivery before 37 weeks of gestation), gestational hypertension, preeclampsia, polyhydramnios, and oligohydramnios were also documented from these records.

The recorded adverse fetal outcomes were infant death, stillbirth, dystocia, bone fracture, nerve palsy, admission to the neonatal intensive care unit (NICU), respiratory complications [including respiratory distress syndrome (RDS) and transient tachypnea of newborn (TTN)] that increased birth weight, macrosomy (birth weight of $>4000 \mathrm{~g}$ ), large for gestational age (LGA, defined as birth weight $>$ the $90^{\text {th }}$ percentile on standard charts), small for gestational age (SGA, defined as birth weight $<$ the $10^{\text {th }}$ percentile on standard charts), and metabolic complications including hypocalcemia, hemoglobin level $\geq 20 \mathrm{~g} / \mathrm{dL}$, hypoglycemia (blood glucose level $\leq 35 \mathrm{mg} / \mathrm{dL}$ ), and hyperbilirubinemia requiring phototherapy.

\section{Results}

The present study included 1360 pregnant women who underwent screening for GDM. Out of the 1360 women screened between September 2012 and October 2013, 380 (28\%) women were diagnosed with GDM, whereas the remaining 980 (72\%) had no GDM. Anthropometric, clinical, and biochemical features of all pregnant women having no GDM risk factors are shown in Table 1.

Maternal age, body mass index (BMI), and weight gain at the time of 75-g OGTT and at delivery were remarkably different between the groups. Glycemic levels in both fasting samples and following the glucose load were also remarkably higher in the GDM group. Out of the 380 women with GDM, 102 (27\%) received insulin, whereas the remaining 278 (73\%) were treat- ed with dietary modifications. The only adverse event in 18 of the 380 women was polyhydramnios.

Logistic regression analysis was performed to test whether the diagnosis of GDM in women younger than 35 years without risk factors influenced maternal and neonatal adverse events despite achieving adequate glycemic control. GDM was the dependent variable in this analysis. Maternal outcomes in women included in the study are shown in Table $2 \mathrm{a}$.

In the GDM group, the rate of primary cesarean section (CS) was significantly higher than that in the non-GDM group [29.6\% vs $15.3 \%$; odds ratio $(\mathrm{OR})=2.35,95 \%$ confidence interval $(\mathrm{CI})$ $1.53-3.64 ; \mathrm{p}<0.001$ ]; furthermore, the difference remained significant after correcting for age, prepregnancy BMI, and parity (Table 2a). The rate of CS after vaginal labor induction was alike in both groups. Secondary CS in women who had previously delivered via CS was strongly associated with GDM [adjusted odds ratio $(\mathrm{AOR})=5.05,95 \% \mathrm{CI} 2.11-12.08, \mathrm{p}<0.001]$. In unadjusted analyses, the combination of gestational hypertension and preeclampsia was associated with $\mathrm{GDM}(\mathrm{OR}=2.44,95 \%$ CI $1.05-5.65, \mathrm{p}=0.037$ ), as was preterm delivery ( $\mathrm{OR}=2.43,95 \%$ CI 1.11-5.29, $\mathrm{p}=0.025)$; however, these associations were insignificant subsequent to adjusting for age, prepregnancy BMI, and parity (for the combination of gestational hypertension and preeclampsia $\mathrm{AOR}=2.03,95 \% \mathrm{CI} 0.83-4.97, \mathrm{p}=0.120$, for preterm delivery $\mathrm{AOR}=1.65,95 \% \mathrm{CI} 0.32-8.51, \mathrm{p}=0.549$ ). The diagnosis of GDM was associated with polyhydramnios even after correcting for age, prepregnancy $\mathrm{BMI}$, and parity $(\mathrm{AOR}=4.48,95 \%$ CI 1.20-16.73, $\mathrm{p}=0.025)$. No association was observed between fetal distress and oligohydramnios (Table 2a). Fetal/neonatal outcomes in the women included in the study are shown in Table $2 \mathrm{~b}$.

No stillbirth, neonatal deaths, or nerve palsy occurred among the infants in either group. The newborns of women with GDM showed a significantly higher weight $(p<0.001)$ after correcting for maternal age, prepregnancy BMI, and gestational age at birth. Additionally, the diagnosis of GDM was strongly associated with admission to NICU following adjustment for age, BMI, parity, and neonatal weight $(\mathrm{AOR}=4.39,95 \% \mathrm{CI} 1.44-13.37, \mathrm{p}=0.009)$. Nevertheless, no significant association was observed between the groups regarding other important perinatal outcomes such as shoulder dystocia and bone fracture $(\mathrm{AOR}=1.47,95 \% \mathrm{CI} 0.81$ - 
Table 2a. Maternal outcomes in women with and without GDM

\begin{tabular}{|c|c|c|c|c|c|c|c|}
\hline Outcome & $\begin{array}{c}\text { GDM } \\
(\mathbf{n}=380)\end{array}$ & $\begin{array}{c}\text { No GDM } \\
(\mathrm{n}=980)\end{array}$ & $\begin{array}{c}\text { OR } \\
(95 \% \mathrm{CI})\end{array}$ & $\begin{array}{c}\mathbf{p} \\
\text { value }\end{array}$ & $\begin{array}{c}\text { OR } \\
(95 \% \mathrm{CI})^{\mathrm{a}}\end{array}$ & $\underset{\text { value }}{\mathbf{p}}$ & $\begin{array}{c}\text { Power } \\
\text { (\%) }\end{array}$ \\
\hline Primary cesarean section, n (\%) & $112(30)$ & $147(15)$ & $2.4(1.5-3.6)$ & $<0.001$ & $1.9(1.2-3.1)$ & 0.006 & $>95$ \\
\hline Secondary cesarean section, $\mathrm{n}(\%)$ & $42(11)$ & $37(4)$ & $3.9(1.8-8.8)$ & 0.001 & $5.1(2.1-12.1)$ & $<0.001$ & 85.2 \\
\hline Cesarean section after labor, n (\%) & $7(2)$ & $27(3)$ & $0.6(0.2-2.4)$ & 0.498 & $0.6(0.1-2.2)$ & 0.401 & 9.7 \\
\hline Labor induction, $\mathrm{n}(\%)$ & $5(1)$ & $4(1)$ & $4.3(0.4-48.1)$ & 0.233 & $3.8(0.3-53.3)$ & 0.314 & 13.5 \\
\hline Gestational hypertension, $\mathrm{n}(\%)$ & $15(4)$ & $15(2)$ & $2.6(0.9-7.8)$ & 0.095 & $1.7(0.7-7.2)$ & 0.173 & 33.4 \\
\hline Preeclampsia, n (\%) & $10(3)$ & $12(1)$ & $2.2(0.6-77.6)$ & 0.223 & $1.7(0.4-6.7)$ & 0.443 & 18.1 \\
\hline Fetal distress, n (\%) & $11(3)$ & $26(3)$ & $1.1(0.4-3.2)$ & 0.896 & $0.9(0.3-3.0)$ & 0.879 & 8 \\
\hline Polyhydramnios, n (\%) & $18(5)$ & $11(1)$ & $4.5(1.3-14.1)$ & 0.016 & $4.5(1.2-16.7)$ & 0.025 & 58.7 \\
\hline Oligohydramnios, n (\%) & $9(2)$ & $7(1)$ & $2.9(0.6-13.1)$ & 0.166 & $1.7(0.3-8.5)$ & 0.549 & 28.5 \\
\hline Preterm delivery, n (\%) & $31(8)$ & $33(3)$ & $2.4(1.1-5.3)$ & 0.025 & $1.9(0.8-4.5)$ & 0.116 & 52.3 \\
\hline Breech presentation, n (\%) & $39(10)$ & $81(8)$ & $1.2(0.7-2.3)$ & 0.502 & $1.2(0.7-2.2)$ & 0.563 & 9.9 \\
\hline
\end{tabular}

Table 2 b. Fetal/neonatal outcomes in women with and without GDM

\begin{tabular}{|c|c|c|c|c|c|c|c|}
\hline Outcome & $\begin{array}{c}\text { GDM } \\
(\mathbf{n}=380)\end{array}$ & $\begin{array}{l}\text { No GDM } \\
(n=980)\end{array}$ & $\begin{array}{c}\text { OR } \\
(95 \% \mathrm{CI})\end{array}$ & $\begin{array}{c}\mathbf{p} \\
\text { value }\end{array}$ & $\begin{array}{c}\text { OR } \\
(95 \% \mathrm{CI})^{\mathrm{a}}\end{array}$ & $\begin{array}{c}\mathbf{p} \\
\text { value }^{\mathrm{a}}\end{array}$ & $\begin{array}{c}\text { Power } \\
\text { (\%) }\end{array}$ \\
\hline Birth weight (kg) & $3.2 \pm 0.4$ & $3.09 \pm 0.3$ & & $0.002^{\mathrm{a}}$ & - & $<0.001^{\mathrm{b}}$ & $>95$ \\
\hline Serious perinatal complications, $\mathrm{n}(\%)$ & $44(12)$ & $84(9)$ & $1.5(0.8-2.6)$ & 0.199 & $1.2(0.7-2.3)^{\mathrm{c}}$ & $0.497^{\mathrm{c}}$ & 17.2 \\
\hline Dystocia, n (\%) & $0(0.0)$ & $0(0.0)$ & - & - & - & - & - \\
\hline Bone fracture, $\mathrm{n}(\%)$ & $4(1.1)$ & $0(0.0)$ & - & - & - & - & - \\
\hline Admission to NICU, n (\%) & $24(6)$ & $14(2)$ & $4.1(1.5-11.4)$ & 0.006 & $4.4(1.4-13.4)^{\mathrm{d}}$ & $0.009^{\mathrm{d}}$ & 68.5 \\
\hline RDS, n (\%) & $6(2)$ & $4(1)$ & $3.3(0.5-19.7)$ & 0.197 & $2.7(0.4-17.4)^{\mathrm{e}}$ & $0.306^{\mathrm{e}}$ & 26.3 \\
\hline TTN, n (\%) & $9(3)$ & $8(1)$ & $2.9(0.7-13.1)$ & 0.167 & $1.9(0.3-10.7)^{\mathrm{e}}$ & $0.472^{\mathrm{e}}$ & 27.8 \\
\hline Macrosomia ( $\geq 4 \mathrm{~kg}$ ), n (\%) & $5(1)$ & $16(2)$ & $1.5(0.2-8.7)$ & 0.694 & $0.5(0.9-2.7)^{\mathrm{c}}$ & $0.482^{\mathrm{c}}$ & 28.7 \\
\hline LGA, n (\%) & $33(9)$ & $18(2)$ & $4.9(1.9-12.4)$ & $<0.001$ & $3.5(1.3-9.3)^{\mathrm{c}}$ & $0.011^{\mathrm{c}}$ & 85.6 \\
\hline SGA, n (\%) & $10(3)$ & $14(2)$ & $1.8(0.5-6.0)$ & 0.331 & $1.9(0.5-7.4)^{\mathrm{c}}$ & $0.311^{\mathrm{c}}$ & 16.5 \\
\hline Metabolic complications, n (\%) & $20(5)$ & $18(2)$ & $2.9(1.0-7.8)$ & 0.040 & $2.3(0.8-7.1)^{\mathrm{c}}$ & $0.137^{\mathrm{c}}$ & 46.6 \\
\hline Hypoglycaemia, n (\%) & $3(1)$ & $0(0.0)$ & - & - & - & - & - \\
\hline Hyperbilirubinemia, n (\%) & $8(2)$ & $6(1)$ & $2.9(0.6-13.1)$ & 0.164 & $1.2(0.2-5.8)^{\mathrm{c}}$ & $0.824^{\mathrm{c}}$ & 27.5 \\
\hline Hypocalcemia, n (\%) & $5(1)$ & $5(1)$ & $2.2(0.3-15.5)$ & 0.443 & $5.3(0.7-41.4)^{\mathrm{c}}$ & $0.113^{\mathrm{c}}$ & 15.4 \\
\hline Polycythemia, n (\%) & $4(1)$ & $5(1)$ & $2.2(0.3-15.5)$ & 0.443 & $2.2(0.3-18.7)^{\mathrm{c}}$ & $0.474^{\mathrm{c}}$ & 15.4 \\
\hline \multicolumn{8}{|c|}{$\begin{array}{l}\text { aCalculated by Mann-Whitney U test. } \\
\text { 'Calculated by linear regression analysis after adjustment for maternal age, prepregnancy BMI, and gestational age at birth. } \\
\text { cValues were obtained by logistic regression analysis after adjustment for maternal age, prepregnancy BMI, parity, and gestational age at birth. } \\
\text { dValues were obtained by logistic regression analysis after adjustment for maternal age, prepregnancy BMI, parity, and neonatal weight. } \\
\text { eValues were obtained with logistic regression after adjustment for maternal age, prepregnancy BMI, parity, and delivery mode. } \\
\text { NICU: neonatal intensive care unit; RDS: respiratory distress syndrome; TTN: transient tachypnea of newborn; LGA: large for gestational age; } \\
\text { SGA: small for gestational age } \\
\text { Power was calculated post hoc with G*Power 3.1, entering R-squared multiple correlation coefficient obtained with regression for each trait } \\
\text { OR: Odd ratio; GDM: Gestational diabetes mellitus }\end{array}$} \\
\hline
\end{tabular}

2.63, $\mathrm{p}=0.202$ ). There was no remarkable difference between the groups regarding SGA or macrosomia, yet significantly more infants in the GDM group were LGA (AOR $=3.53,95 \% \mathrm{CI}$
1.34-9.34, $\mathrm{p}=0.011)$. Neonatal respiratory problems at delivery, including RDS and TTN, were not significantly different between the two groups. GDM appeared to be associated with 
metabolic complications ( $\mathrm{OR}=2.86,95 \% \mathrm{CI} 1.05-7.80, \mathrm{p}=0.040)$, although this association was not observed after correcting for age, BMI, parity, and gestational age at birth. All significant associations were independent of BMI; however, prepregnancy BMI was correlated with primary CS $(r=0.103, p=0.017)$, neonatal weight $(\mathrm{r}=0.122, \mathrm{p}=0.005)$, and LGA $(\mathrm{r}=0.113, \mathrm{p}=0.009)$ independently from GDM via Pearson's test.

\section{Discussion}

GDM is a type of diabetes and is the most common metabolic disorder seen during gestation occurring in 1\%-14\% of pregnancies (1). The prevalence of GDM continues to increase globally (7). GDM may cause serious morbidities both for mother and infant (8). Women with GDM have been reported to have increased rates of stillbirth, polyhydramnios, gestational hypertension, macrosomia, and cesarean delivery (9). GDM usually resolves after delivery, but it appears that the risk of recurring GDM and type 2 diabetes mellitus are increased in subsequent pregnancies, along with cardiovascular risk later in life $(10,11)$. Although the precise role of the risk factors related to GDM (multiparity, obesity,) has not yet been entirely defined, they may be included in the classification of pregnancy-related or maternal factors (12). Early diagnosis of metabolic disorder is highly critical for the prevention of fetal and maternal complications $(5,13)$.

Since the adoption of the $2 \mathrm{~h} 75-\mathrm{g}$ OGTT in pregnancy, the WHO recommended the same diagnostic limit values accepted for the identification of impaired glucose tolerance in nonpregnant women $(14,15)$. The WHO stated in 1999 that GDM encompasses both impaired glucose tolerance and diabetes (fasting plasma glucose $\geq 7 \mathrm{mmol} / \mathrm{dL}$ or $\geq 126 \mathrm{mg} / \mathrm{dL} ; 2$ h plasma glucose $\geq 7.8 \mathrm{mmol} / \mathrm{dL}$ or $140 \mathrm{mg} / \mathrm{dL}$, respectively) (16) and has maintained their recommendations to date.

With early diagnosis and good medical and obstetric care, the risks of higher perinatal mortality and infant morbidity rates associated with GDM should be minimized $(17,18)$. In patients with persistent maternal hyperglycemia, the use of additional oral medications, insulin treatment, and lifestyle changes has shown improved perinatal outcomes. Medical nutrition counseling and diet therapy to achieve an overall healthy lifestyle are valuable in the management of GDM (19-21) and can optimize maternal and fetal outcomes $(22,23)$.

In this study, our aims were to verify the effectiveness of the WHO GDM diagnostic criteria in preventing adverse maternal and neonatal outcomes in women younger than 35 years with no apparent risk factors for GDM and to verify the effectiveness of dietary modifications in those outcomes. With no prior knowledge of any risk factors, 1360 pregnant women underwent OGTT at the 24th-28th gestational weeks. Approximately $28 \%$ of them were diagnosed with GDM and subsequently treated, thus reducing the risk of adverse maternal and neonatal hyperglycemia-related events, including high rates of primary $\mathrm{CS}$, polyhydramnios, preterm delivery, admission to NICU, LGA, and higher neonatal weight.

The rate of adverse events in this group was similar to all the other women with GDM. Similar findings have been recently reported $(24,25)$.
While women with GDM were significantly older and had a significantly higher BMI compared with their non-GDM counterparts, all observed associations remained significant after correcting for age and prepregnancy BMI, indicating that GDM was an independent risk factor. Our findings confirm and extend previous observations that GDM and increased BMI are independently associated with adverse maternal and neonatal outcomes, with their combination having a greater impact. Some adverse pregnancy outcomes in our study were correlated with prepregnancy BMI even within the normal range $\left(<25 \mathrm{~kg} / \mathrm{m}^{2}\right)$ and independently from GDM. Our results show that most cases of GDM were diagnosed at baseline and at $2 \mathrm{~h}$ of the OGTT timeframe.

The interpretation of the results of this study is limited by the small sample size. Higher rates of preterm delivery observed among the GDM cases together with the increase in both CS and NICU admission rates may be considered to be the result of excessive medical interventions. However, the higher rate of polyhydramnios and LGA in women with GDM accounted for the higher number of $\mathrm{CS}$ in this group, whereas overtreatment would not help explain the neonatal primary outcomes, such as LGA, and higher neonatal weight. All outcomes in our GDM group are remarkably lower with respect to those observed in other studies of GDM in the general population (25).

There are only a few studies on GDM prevalence reported from Turkey. In the study by Akbay et al. (26), a prevalence of $8.9 \%$ was reported, whereas Köşüş et al. (27) reported a prevalence of $8.6 \%$. In both these studies, GDM was diagnosed after a 50 -g glucose screening test followed by a 100 -g glucose OGTT in two steps. While only a few studies using the 75-g OGTT according to the WHO criteria have been reported in literature, this method has the advantage of being both a screening and diagnostic test and being performed in a single step. Additional, larger studies are needed to confirm our findings.

Ethics Committee Approval: Ethics committee approval was received for this study from the ethics committee of İstanbul Medipol University.

Informed Consent: Written informed consent was obtained from patients who participated in this study.

Peer-review: Externally peer-reviewed.

Author contributions: Concept - L.H.A.; Design - L.H.A.; Supervision L.H.A.; Resource - L.H.A., B.Y.; Materials - L.H.A., B.Y., M.A., D.U.; Data Collection\&/or Processing - L.H.A., B.Y.; Analysis\&/or Interpretation L.H.A., B.Y.; Literature Search - L.H.A., B.Y., M.A.; Writing - L.H.A.; Critical Reviews - D.U., B.Y.

Conflict of Interest: No conflict of interest was declared by the authors.

\section{References}

1. Cunningham FG, Leveno KG, Bloom SL, Hauth JC, Gilsrab LC, Wenstrom KD. Williams Obstetrics. New York: McGraw Hill; 2005. p. 1170-2.

2. Fauci AS, Braunwald E, Kasper DI, Hauser SL, Longo DL, Jameson JL, Loscalzo J. Harrison's principles of Internal Medicine. New York: McGraw Hill Medical; 2008. p. 631.

3. Fernandez-Real JM, Lopez BA, Richard W. Cross talk between iron metabolism and diabetes. Diabetes 2002; 51: 2348-54. [CrossRef] 
4. International Association of Diabetes and Pregnancy Study Groups Consensus Panel. International Association of Diabetes and Pregnancy Study Groups recommendations on the diagnosis and classification of hyperglycemia in pregnancy. Diabetes Care 2010; 33: 676-82. [CrossRef]

5. Griffin ME, Coffery M, Johnson H, Scanlon P, Foley M, Stronge J, et al. Universal vs. risk factor-based screening for gestational diabetes mellitus: Detection rates, gestation at diagnosis and outcome. Diabetes Med 2000; 17: 26-32. [CrossRef]

6. American Diabetes Association. Gestational diabetes mellitus. Diabetes Care 2003; 26: p. 103-5. [CrossRef]

7. American Diabetes Association. Diagnosis and classification of diabetes mellitus. Diabetes Care. 2007; 30: p. 45-6.

8. Kjos SL, Buchanan TA. Gestational diabetes mellitus. N Engl J Med 1999; 341: 1749-56. [CrossRef]

9. Keshavarz M, Cheung NW, Babaee GR, Moghadam HK, Ajami ME, Shariati M. Gestational diabetes in Iran: incidence, risk factors and pregnancy outcomes. Diabetes Res Clin Pract 2005; 69: 279-86. [CrossRef]

10. Bo S, Monge L, Macchetta C, Menato G, Pinach S, Uberti B, Pagano G. Prior gestational hyperglycemia: a long-term predictor of the metabolic syndrome. J Endocrinol Invest 2004; 27: 629-35. [CrossRef]

11. Retnakaran R, Qi Y, Connelly PW, Sermer M, Zinman B, Hanley AJ. Glucose intolerance in pregnancy and postpartum risk of metabolic syndrome in young women. J Clin Endocrinol Metab 2010; 95: 670-7. [CrossRef]

12. Ben-Haroush A, Yogev Y, Hod M. Epidemiology of gestational diabetes mellitus and its association with Type 2 diabetes. Diabet Med 2004; 21: 103-13. [CrossRef]

13. Sayah SH, Chondra A, Eberhardt MS. Pregnancy experience among women with and without gestational in the U.S. 1995 national survey of family growth. Diabetes Care 2005; 28: 1035-40. [CrossRef]

14. Classification and diagnosis of diabetes mellitus and other categories of glucose intolerance. National Diabetes Data Group. Diabetes 1979; 28: 1039-57. [CrossRef]

15. WHO Expert Committee on Diabetes Mellitus: second report. World Health Organ Tech Rep Ser. 1980; 646: 1-80.

16. Alberti KG, Zimmet PZ. Definition, diagnosis and classification of diabetes mellitus and its complications. Part 1: diagnosis and classification of diabetes mellitus provisional report of a WHO consultation. Diabet Med 1998; 15: 539-53. [CrossRef]
17. Beischer NA, Wein P, Sheedy MT, Steffen B. Identification and treatment of women with hyperglycaemia diagnosed during pregnancy can significantly reduce perinatal mortality rates. Aust N Z J Obstet Gynaecol 1996; 36: 239-47. [CrossRef]

18. Langer $\mathrm{O}$. Is normoglycemia the correct threshold to prevent complications in the pregnant diabetic patient? Diabetes Rev 1996; 4: 2-10.

19. American Diabetes Association, Bantle JP, Wylie-Rosett J, Albright AL, Apovian CM, Clark NG, et al. Nutrition recommendations and interventions for diabetes: a position statement of the American Diabetes Association. Diabetes Care 2008; 31 (Suppl1): 61-78. [CrossRef]

20. Reader DM. Medical nutrition therapy and lifestyle interventions. Diabetes Care 2007; 30 (Suppl2): 188-93. [CrossRef]

21. Reader D, Splett P, Gunderson EP, Diabetes Care and Education Dietetic Practice Group. Impact of gestational diabetes mellitus nutrition practice guidelines implemented by registered dietitians on pregnancy outcomes. J Am Diet Assoc 2006; 106: 1426-33. [CrossRef]

22. Han S, Crowther CA, Middleton P, Heatley E. Different types of dietary advice for women with gestational diabetes mellitus. Cochrane Database Syst Rev 2013; 3: CD009275.

23. Walker JD. NICE guidance on diabetes in pregnancy : management of diabetes and its complications from preconception to postnatal period. NICE clinical guideline 63. London, March 2008. Diabet Med 2008; 25: 1025-7. [CrossRef]

24. Cosson E, Benbara A, Pharisien I, Nguyen MT, Revaux A, Lormeau B, et al. Diagnostic and prognostic performances over 9 years of a selective screening strategy for gestational diabetes mellitus in a cohort of 18, 775 subjects. Diabetes Care 2013; 36: 598-603 [CrossRef]

25. Avalos GE, Owens LA, Dunne F, ATLANTIC DIP Collaborators. Applying current screening tools for gestational diabetes mellitus to a European population-is it time for change? Diabetes Care 2013; 36: 3040-4. [CrossRef]

26. Akbay E, Torun Si, Yalçınkaya H, Uzunçakmak C, Tokluca G. Prevalence of gestational diabetes among pregnant women attending in MD Sadi Konuk Training and Research Hospital. Turkiye Klinikleri J Gynecol Obst 2010; 20: 170-5.

27. Kosus N, Kosus A, Duran M, Turhan NO. Effect of number of abnormal oral glucose tolerance test (OGTT) values on birthweight in women with gestational diabetes. Indian J Med Res 2013; 137: 95-101. 